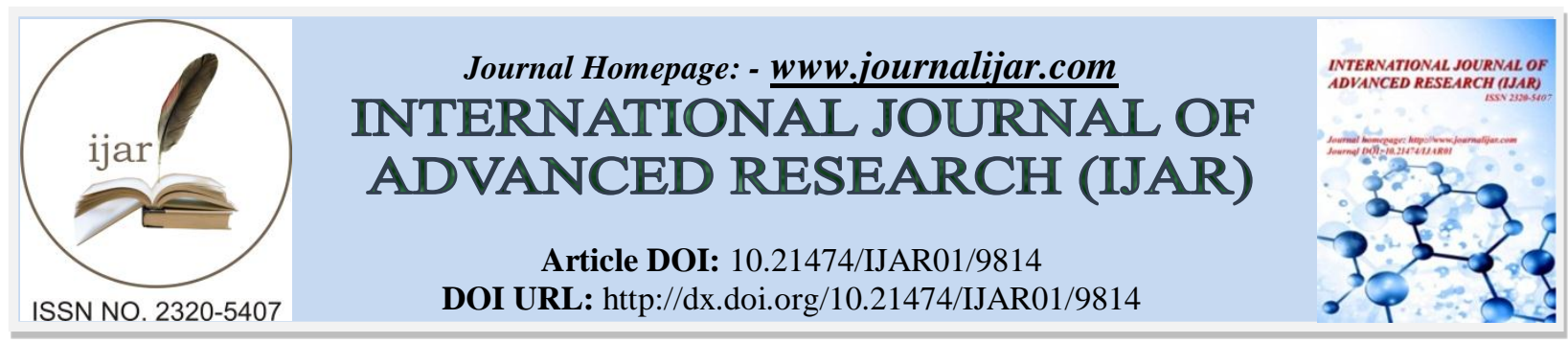

RESEARCH ARTICLE

\title{
OPTIMIZATION OF POLYMER TOUGHENING PROCESS OF SOLID HYDROXYAPATITE IMPLANT.
}

Prof. Tawfik Taher AJAAL

Faculty of Engineering, Gharyan University, Ministry of Education - Libya.

\section{Manuscript Info}

\section{Manuscript History}

Received: 04 August 2019

Final Accepted: 06 September 2019

Published: October 2019

Key words:-

Calcium phosphates, Polycaprolactone,

Toughening, Compact pellets,

Mechanical properties.

\begin{abstract}
The experimental work of this study was conducted using a statistical experimental design in conjunction with the Taguchi method for optimization. The most effective factors affecting the toughening of the ceramic pellets were evaluated. The target of this experimental work was to maximize the product strength and minimize the amount of deposited polymer on the product. The Taguchi signal-to-noise $(\mathrm{S} / \mathrm{N})$ ratio was used for the optimization process. The experiments were divided into three stages. Stage One was identifying the parameters and the determination of the range of values to be explored; this step is usually done through literature review and simple experiments. Stage Two was the screening experiments (process characterization) to find out the most significant parameters effects on the process; this stage is done through the design of an orthogonal array based on the number of the input factors into the process. Stage Three was the optimization process itself ${ }^{[1-10]}$. Stages One and Two were reported in a previous study ${ }^{[9]}$. Stage Three is the subject of this study; for this stage the levels of the candidate factors were narrowed for more precise optimization. Four candidate factors with three levels were tried using an $\mathrm{L}_{9}\left(3^{4}\right)$ orthogonal array. The results were optimized using a statistical experimental design using the analysis of means and orthogonal array. The excess polymer removal technique used and the number of polymer solution coatings showed major effects on the flexural strength. Presumably, because these affect the mass of polymer applied. Optimum values of the flexural strength and mass of polymer were determined using statistical experimental design and the Taguchi method. Using the optimum experimental condition for preparing samples produces high quality in dense implants with $10.49 \mathrm{MPa}$ flexural strength and $80 \mu \mathrm{m}$ thickness of the deposited polymer, with mass of $21.0 \mathrm{mg} / \mathrm{sample}$.
\end{abstract}

Copy Right, IJAR, 2019, All rights reserved.

\section{Introduction}

Orthopedic practice often requires the use of synthetic bone-graft material to replace missing or severely damaged natural bone ${ }^{[11-23]}$. Ideally, such material would be biocompatible ${ }^{[21-29]}$, suitably bioactive so that the implanted material may be fully remodeled ${ }^{[18-24]}$, and adequately tolerant of mechanical orthopedic fixation ${ }^{[25-27]}$. Due to the chemical similarity with bones and perfect biocompatibility, the majority of bone substituting materials are made of 
(or covered by) calcium phosphates ${ }^{[28-30]}$. However, the mechanical properties of calcium phosphate based bioceramics are poor; the samples are brittle and cannot be easily shaped to the desired dimensions and form ${ }^{[31-33]}$, so the application of calcium phosphates in surgery is reduced.

Polymer coatings are proposed to toughen ceramic implants because of the flexible properties of polymers. A polymer coating applied to the surfaces of a porous but compact ceramic implant would maintain the desirable porous structure. The incorporation of a biodegradable polymer to an implant material would minimize fragmentation following mechanical fixation ${ }^{[34-41]}$, provide further increase in strength and toughness in keeping with the high-load performance requirements, and provide well-characterized binding sites for selected pharmaceutical agents ${ }^{[42-51]}$. This study deals with preliminary experiments with compact pellets as fore-runners to those with scaffolds in order to determine the principal features of the toughening with biodegradable polymer coatings.

The mechanical properties of the polymer coated ceramic implants are affected by various factors such as the technique used to remove the excess polymer solution, concentration of polymer, heat treatment temperature, number of coatings and so on. In this study, the influence of these factors on the flexural strength and the amount of the deposited polymer in the samples was analyzed. The interrelationships between the above factors are complex, and the analysis of this system to optimize the factors is a time and labor-consuming work. Hence, the analyses using conventional methods are inefficient.

In this study, statistical experimental design and Taguchi's parameter design were carried out simultaneously. The first can be considered as a raw data analysis (it focuses on the measured value itself) and the latter is the S/N data analysis. By raw data analysis, the effects of several factors on the mechanical strength were analyzed. The excess polymer solution removal method, concentration of polymer, heat treatment temperature and the number of coatings were chosen as significant factors. The influence of these factors was analyzed by S/N data analysis. The purpose of this study was to evaluate the effect of several factors on the mechanical strength of the ceramic implant coated with polymer and to optimize these factors using a statistical experimental design and the Taguchi's parameter design.

\section{Methodology:-}

\section{Processing of Dense Ceramic Pellets}

The green ceramic pellets consisted of a mixture of silica-contained hydroxyapatite $\left(\mathrm{Si}-\mathrm{HA}\right.$ ) powder (with $\mathrm{the}_{\mathrm{SiO}}$ : $\mathrm{HA}$ ratio $=1: 1$ ) and polyvinyl acetate/retained sol binder. The Si-HA was prepared by the sol gel method described in detail elsewhere ${ }^{[52 \& 53]}$. Pellets weight used was $0.25 \pm 0.01 \mathrm{gm}$ of Si-HA. The mixture was then added into an 11 $\mathrm{mm}$ diameter die and pressed for approximately 30 seconds under $20.3 \mathrm{Mpsi}$. Later on, the pellets were sintered at $1250^{\circ} \mathrm{C}$ for 2 hours. Resulting pellets were approximately $11 \mathrm{~mm}$ in diameter, $1.1 \mathrm{~mm}$ thick, and $0.25 \mathrm{gm}$ in weight.

\section{Preparation of PCL solutions}

10,12 , and $14 \%$ (weight by volume) solutions of polycaprolactone, PCL, (average molecular weight 80,000 Da) were prepared by dissolving of 10,12 , or $14 \mathrm{gm}$ of PCL in $100 \mathrm{ml}$ of dichloromethane, respectively. These particular concentrations were used as recommended in a previous study [9]. The solutions were put into closed glass vessels and shaken over-night to complete dissolution.

\section{Polymer Coating of Samples}

A simple dipping method was used for all samples. However, three different techniques for removing excess of the polymer solution were employed. The first one consisted of careful removal of the sample from the polymer solution with no removal of excess solution (no shacking). The second technique used was shaking by hands for 30 seconds (hand shaking). The final technique required immediate rotation of the sample for 30 seconds, in a closed metallic cylinder at a speed of 1000 RPM.

The number of dipping into the polymer solution, the concentration of the polymer solution and heat treatment were three other important variables. 2, 3, and 4 dipping in either 10, 12 or $14 \%$ polymer solutions were used. After dipping, each sample was allowed to dry for 15 minutes at room temperature. Following this, the samples were heated in an oven at 50,60 or $70{ }^{\circ} \mathrm{C}$ for 30 minutes.

\section{Taguchi Design of Experiments [1-5]}

Four parameters were examined in the polymer coating process of the pellet samples as shown in Table 1 
Table 1 -Coating Process Parameters

\begin{tabular}{|l|l|l|l|l|}
\hline & \multicolumn{1}{|c|}{ Parameter } & \multicolumn{3}{c|}{ Levels } \\
\hline Symbol & & 1 & 2 & 3 \\
\hline $\mathrm{a}$ & A - Removal tech. & No shaking & Hand-shaking & Spin-coating \\
\hline b & B - Number of dipping & 2 & 3 & 4 \\
\hline c & C- Heat treatment & $50{ }^{\circ} \mathrm{C}$ & $60^{\circ} \mathrm{C}$ & $70^{\circ} \mathrm{C}$ \\
\hline $\mathrm{d}$ & D- Conc. of polymer & $10 \%$ & $12 \%$ & $14 \%$ \\
\hline
\end{tabular}

The orthogonal array $\mathrm{L}_{9}\left(3^{4}\right)$ was chosen for the optimization of the coating process, as detailed in Table 2 . Eight samples were prepared for each trial.

Table 2- L9 Orthogonal array

\begin{tabular}{|c|l|c|c|c|}
\hline Experiment \# & $\begin{array}{l}\text { A } \\
\text { Removal }\end{array}$ & $\begin{array}{l}\text { B } \\
\text { \# of Dipping }\end{array}$ & $\begin{array}{l}\text { C Heat Treatment } \\
\text { Heation }\end{array}$ & $\begin{array}{l}\text { D } \\
\text { PCL Concentration }\end{array}$ \\
\hline 1 & Hand Shaking & 2 & $50^{\circ} \mathrm{C}$ & $10 \%$ \\
\hline 2 & Hand Shaking & 3 & $60^{\circ} \mathrm{C}$ & $12 \%$ \\
\hline 3 & Hand Shaking & 4 & $70^{\circ} \mathrm{C}$ & $14 \%$ \\
\hline 4 & Spin & 2 & $60^{\circ} \mathrm{C}$ & $14 \%$ \\
\hline 5 & Spin & 3 & $70^{\circ} \mathrm{C}$ & $10 \%$ \\
\hline 6 & Spin & 4 & $50^{\circ} \mathrm{C}$ & $12 \%$ \\
\hline 7 & No Shaking & 2 & $70^{\circ} \mathrm{C}$ & $12 \%$ \\
\hline 8 & No Shaking & 3 & $50^{\circ} \mathrm{C}$ & $14 \%$ \\
\hline 9 & No Shaking & 4 & $60^{\circ} \mathrm{C}$ & $10 \%$ \\
\hline
\end{tabular}

The Signal-to-Noise (S/N) Ratio

For the optimization process of this experimental work, two cases of Taguchi signal-to-noise (S/N) ratio were chosen, namely "more-is-better" for maximizing the measured response, and less-is-better in the case of minimizing the response as illustrated below:

The case for the optimal response being a maximum is referred to as the more-is-better (MB) case, which is appropriate for examining a process where it is desired that the mechanical strength of the product material should be maximum. The Taguchi $\mathrm{S} / \mathrm{N}$ ratio here is then [1-4]:

$$
\eta_{M B}=-10 \log _{10}\left(\frac{1}{n} \sum_{i=1}^{n} \frac{1}{y_{i}^{2}}\right)
$$

When the optimal response is desired to be a minimum, such as the amount of polymer deposited on the sample in this study, we have the less-is-better (LB) case, where the Taguchi S/N function becomes [1-4]:

$$
\eta_{L B}=-10 \log 10\left(\frac{1}{n} \sum_{i=1}^{n} y_{i}^{2}\right)
$$

Thus in the case of developing an effective but economic process to coat pellets, we are concerned primarily with two "properties" (strength and mass of polymer deposited), and we are investigating various "factors" (processing variables) in order to arrive at the optimal combination of high strength with the amount of polymer mass used at a minimum. In this way, we aim to define the processing conditions to produce pellets with acceptable strength but at minimum materials cost.

\section{Mass and Polymer Thickness Measurements on Pellets}

Before coating, the initial mass of each dense pellet was determined. After coating, the mass of each pellet was measured again. Therefore, for each experimental trial, the amount of polymer adsorbed on each pellet was known. The surface area of the pellets was estimated as follows:

$$
S_{\text {pellet }}=2 \pi R^{2}+2 \pi R H
$$


where: $\mathbf{R}$ is the radius of the pellet

$\mathbf{H}$ is the thickness of the pellet

We assumed that the polymer coating was homogeneous and even. The density of PCL $\left(1.146 \mathrm{~g} / \mathrm{cm}^{3}\right)$ was considered similar for all concentrations. Based on these assumptions, the thickness of the polymer coating formed on the pellets was estimated as follows:

$$
h=\frac{m S_{\text {pellet }}}{\rho}
$$

where: $\mathbf{h}$ is the PCL thickness on the surface of a pellet

$\mathbf{m}$ is the mass of polymer deposited on pellet

$\boldsymbol{\rho}$ is the density of PCL

An average PCL thickness was recorded for each pellet trial.

\section{Three Point Bending Test}

A small three-point bending jig was designed and built by joining a small steel rod ( $3 \mathrm{~mm}$ in diameter) perpendicular to a larger rod. The sample holder consisted of a further two rods (also $3 \mathrm{~mm}$ in diameter) joined to a metal block and placed $1 \mathrm{~cm}$ apart. A groove was made in the centre of the block to allow alignment of the load. Three-point bending tests were carried out on an Instron machine set for flexural strength. The Instron machine was calibrated with a full-scale load of $100 \mathrm{Kg}$ and a crosshead displacement rate of $0.033 \mathrm{~mm} / \mathrm{min}$. The sample holder with a pellet was inserted placed centrally in the machine with the loading rod at a small distance from the sample. At this point the cross head was activated and the sample tested until a significant drop in load was indicated. The broken sample was removed from the jig, and the process was repeated with each pellet from all trials.
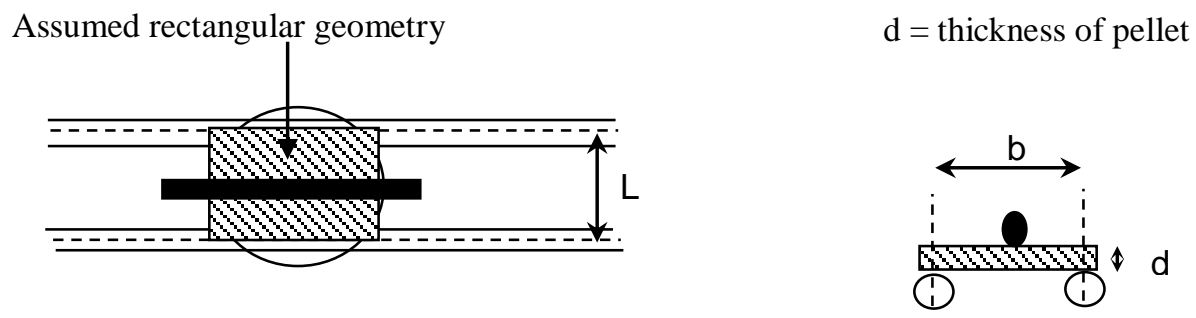

Figure - Three Point Bending Jig and Assumptions

Load versus displacement graphs were plotted for each sample from the data obtained during testing. The maximum load / load at fracture for each sample were determined from the maximum point on the graphs. Using calculations based on a rectangular geometry, the flexural strengths of the samples were determined:

$$
\sigma=\text { stress }=\frac{M c}{I}
$$

where: $\mathbf{M}=$ maximum bending moment

$\mathbf{c}=$ distance from centre of

specimen to outer fibers

$\mathbf{I}=$ moment of inertia of cross section

\begin{tabular}{|c|c|c|c|c|}
\hline & $\mathrm{M}$ & $\mathrm{c}$ & I & $\sigma$ \\
\hline \multirow{2}{*}{ Rectangular } & $F L$ & $d$ & $b d^{3}$ & $3 F L$ \\
\hline & 4 & 2 & 12 & $2 b d^{2}$ \\
\hline
\end{tabular}

$\mathbf{F}=$ applied load 


$$
\sigma_{f s}=\frac{3 F_{f} L}{2 b d^{2}}
$$

where: $\mathbf{F}_{\mathbf{f}}$ is the load at fracture, $\mathbf{L}$ is the distance between support points and the other parameters are indicated in Figure 2.

\section{Scanning Electron Microscopy}

The thickness of the polymeric coatings formed on the dense pellets (one pellet from each trial was studied) was measured by scanning electron microscopy after three-point bending test had been performed. Firstly, the samples were sputtered with gold to provide the surface conductivity necessary for use in the SEM. The samples were placed in the SEM and studied under various magnifications. Finally, images were photographed representing the surface features of the specimens.

\section{Experimental Results and Discussion}

To find the optimal factor levels of the system a series of experiments were conducted. This has been done following an $\mathrm{L}_{9}$ orthogonal array that uses narrower ranges of the factor levels near the initially predicted optimal settings. The most significant factors are the polymer removal method, number of coatings, heat treatment temperature and the polymer concentration. An "analysis of means", ANOM, was used to determine the effects of parameter changes on the mechanical strength and the deposited mass of polymer for the coated pellets. The results were used to determine the effect of each of the parameters on the measured responses. Tables $3-5$ show the raw experimental data and the mean values of the measured responses, as well as the parameter effects on the flexural strength and the amount of polymer deposited in the samples after the coating process.

The effects of the parameters on the flexural strength and $\eta_{M B}$ for the pellet samples are shown in Figure 2. Of the parameters tested, the polymer concentration and the polymer removal technique have the largest effects on the flexural strength with the number of coatings and the heat treatment temperature having smaller effect. The predicted maximum flexural strength should be obtained for a sample prepared with "no shaking" technique, coated three times, heat treated at $70{ }^{\circ} \mathrm{C}$ and $14 \%$ polymer concentration. An examination of the plot for $\eta_{\mathrm{MB}}$ (bottom plot in Figure 2) for the flexural strength shows that the effects on this response are very similar to those for the actual value of the flexural strength. Comparison of the parameter effects on the flexural strength and $\eta_{M B}$ shows that parameter effects are remarkably similar for the response, indicating that strength rather than variability dominated $\eta_{\mathrm{MB}}$.

The effects of the parameters on the deposited mass of polymer on the pellet samples and $\eta_{\mathrm{LB}}$ are shown in Figure 3 . In this case, the spinning technique, the number of coatings, and the polymer concentration have large effects, while the heat treatment shows a small effect. Examination of the plot $\eta_{\mathrm{LB}}$ (bottom plot of Figure 3) for the mass of polymer shows that the effects on the response are similar to the actual response (top plot of Figure 3). The predicted minimum mass of polymer should be obtained for samples prepared with the spinning technique, coated twice, heattreated at $50^{\circ} \mathrm{C}$ and $10 \%$ of polymer concentration. The response dominates the variability in determining the signalto-noise ratio, as shown by the fact that parameter levels that result in lower mass of polymer also results in high value of $\eta_{\mathrm{LB}}$, since it is always desirable to maximize the signal-to-noise ratio. Figure 4 shows the surface SEM micrographs of the experimental trials for the pellet samples. Trials 1, 8, 9 show a porous structure of the polymer coating. The heat treatment of these trials was below the melting point of the polymer; as a result, the coating structure was not even, as can be seen in trials 2, 3, 7 where the samples of these trials were heat treated at temperatures $60 \& 70{ }^{\circ} \mathrm{C}$. Trials $4,5,6$ show the minimum amount of polymer deposited on the surface due to the removal technique used in these trials, i.e. the spinning technique. Figure 5 shows the SEM micrographs of the cross-section of all the trials. The thickness of the deposited polymer on the surfaces of the pellets was calculated for the optimum experimental conditions to be approximately $80 \mu \mathrm{m}$. 
Table 3- Mean values of the flexural strength and mass deposited for the pellets

\begin{tabular}{|l|l|l|l|l|l|l|l|l|l|l|}
\hline \multicolumn{10}{|c|}{ Flexural Strength (MPa) } \\
\hline Sample \# & Uncoated & Trial 1 & Trial 2 & Trial 3 & Trial 4 & Trial 5 & Trial 6 & Trial 7 & Trial 8 & Trial 9 \\
\hline 1 & 3.492 & 5.795 & 16.090 & 16.400 & 4.519 & 8.152 & 4.927 & 5.696 & 24.840 & 7.478 \\
\hline 2 & 4.537 & 9.830 & 9.165 & ----- & 4.696 & 3.529 & 4.592 & ------ & 17.210 & 7.727 \\
\hline 3 & 4.479 & 7.722 & 7.668 & 11.750 & ----- & 8.898 & 2.619 & 4.922 & 26.370 & 7.170 \\
\hline 4 & 4.049 & 4.945 & 8.433 & 25.640 & ----- & 5.071 & 4.456 & 5.646 & ----- & 6.202 \\
\hline 5 & 4.053 & 4.945 & 5.316 & 12.480 & 4.013 & 7.677 & 2.827 & 7.415 & 13.460 & 7.722 \\
\hline 6 & 2.995 & 6.401 & 6.243 & 16.750 & 4.465 & 4.153 & 1.814 & 10.420 & 8.166 & 4.619 \\
\hline 7 & 4.144 & 6.998 & 10.410 & 13.130 & 3.257 & 5.406 & 6.329 & 10.690 & 10.720 & 8.410 \\
\hline 8 & --- & 3.533 & 4.298 & 13.020 & 4.081 & 3.791 & 3.882 & 7.469 & 9.052 & 7.772 \\
\hline Mean & 3.964 & 6.271 & 8.453 & 15.596 & 4.172 & 5.835 & 3.931 & 7.465 & 15.688 & 7.138 \\
\hline \multicolumn{7}{|c|}{ Polymer Deposited mass (gm) } & & & & \\
\hline Sample \# & Uncoated & Trial 1 & Trial 2 & Trial 3 & Trial 4 & Trial 5 & Trial 6 & Trial 7 & Trial 8 & Trial 9 \\
\hline 1 & -- & 0.010 & 0.020 & 0.040 & 0.005 & 0.004 & 0.007 & 0.012 & 0.035 & 0.019 \\
\hline 2 & -- & 0.010 & 0.019 & 0.042 & 0.004 & 0.005 & 0.006 & 0.019 & 0.043 & 0.022 \\
\hline 3 & -- & 0.010 & 0.027 & 0.042 & 0.005 & 0.005 & 0.007 & 0.016 & 0.039 & 0.026 \\
\hline 4 & -- & 0.011 & 0.027 & 0.052 & 0.005 & 0.007 & 0.005 & 0.017 & 0.036 & 0.025 \\
\hline 5 & -- & 0.010 & 0.027 & 0.035 & 0.006 & 0.004 & 0.006 & 0.015 & 0.039 & 0.026 \\
\hline 6 & -- & 0.014 & 0.025 & 0.046 & 0.005 & 0.006 & 0.006 & 0.014 & 0.028 & 0.023 \\
\hline 7 & -- & 0.017 & 0.025 & 0.046 & 0.006 & 0.007 & 0.008 & 0.013 & 0.033 & 0.028 \\
\hline 8 & -- & 0.010 & 0.026 & 0.040 & 0.005 & 0.005 & 0.005 & 0.015 & 0.038 & 0.030 \\
\hline Mean & -- & 0.012 & 0.025 & 0.043 & 0.005 & 0.005 & 0.006 & 0.015 & 0.036 & 0.025 \\
\hline
\end{tabular}

Table 4-Mean of the means of the flexural strength and deposited mass of polymer for pellets

\begin{tabular}{|l|l|l|l|l|l|}
\hline \multicolumn{2}{|c|}{ Trials \& Samples } & \multicolumn{2}{l|}{ Flexural strength $(\mathrm{MPa})$} & \multicolumn{2}{l|}{ Mass of Polymer $(\mathrm{gm})$} \\
\hline Trial \# & \# of samples & Mean & $\eta_{\mathrm{MB}}$ & Mean & $\eta_{\mathrm{LB}}$ \\
\hline Uncoated & 8 & 3.964 & & 0.000 & \\
\hline 1 & 8 & 6.271 & 27.42 & 0.012 & -21.41 \\
\hline 2 & 8 & 8.453 & 29.04 & 0.025 & -27.85 \\
\hline 3 & 8 & 15.596 & 35.44 & 0.043 & -32.70 \\
\hline 4 & 8 & 4.172 & 24.24 & 0.005 & -14.25 \\
\hline 5 & 8 & 5.835 & 25.54 & 0.005 & -14.79 \\
\hline 6 & 8 & 3.931 & 22.22 & 0.006 & -16.02 \\
\hline 7 & 8 & 7.465 & 28.94 & 0.015 & -23.68 \\
\hline 8 & 8 & 15.688 & 34.14 & 0.036 & -31.27 \\
\hline 9 & 8 & 7.139 & 29.04 & 0.025 & -27.99 \\
\hline Mean & 8 & 8.283 & 28.45 & 0.0191 & -23.33 \\
\hline
\end{tabular}

Table 5-Parameter effects on the flexural strength and mass of polymer measurements and the signal-to-noise (S/N) ratio for pellets

\begin{tabular}{|l|l|l|l|l|l|l|l|l|}
\hline \multicolumn{4}{|c|}{ Flexural Strength (MPa) } & \multicolumn{4}{l|}{ Mass of polymer (gm) } \\
\hline \multirow{3}{*}{$\begin{array}{l}\text { Removal } \\
\text { technique }\end{array}$} & $\#$ & Value & Effect & $\eta_{\text {MB }} \mathrm{dB}$ & $\#$ & Value & Effect & $\eta_{\text {MB }} \mathrm{dB}$ \\
\cline { 2 - 9 } & 8 & H. shake & 1.814 & 2.26 & 8 & H. shake & 6.35 & -4.32 \\
\cline { 2 - 9 } & 8 & Spin & 1.823 & 2.18 & 8 & Spin & 7.18 & -3.99 \\
\hline \multirow{3}{*}{$\begin{array}{l}\text { Number of } \\
\text { coatings }\end{array}$} & 8 & No Shake & -3.637 & -4.45 & 8 & No Shake & -13.53 & 8.31 \\
\cline { 2 - 9 } & 8 & 2 & -2.314 & -1.58 & 8 & 2 & -8.53 & 3.55 \\
\cline { 2 - 9 } & 8 & 4 & 1.709 & 1.13 & 8 & 3 & 2.97 & -1.31 \\
\hline \multirow{3}{*}{ Heat Treatment } & 8 & $50^{\circ} \mathrm{C}$ & 0.605 & 0.45 & 8 & 4 & 5.56 & -2.24 \\
\cline { 2 - 9 } & 8 & $60^{\circ} \mathrm{C}$ & -1.696 & -1.00 & 8 & $60^{\circ} \mathrm{C}$ & -1.07 & 0.43 \\
\cline { 2 - 9 } & 8 & $70^{\circ} \mathrm{C}$ & 1.349 & 1.53 & 8 & $70^{\circ} \mathrm{C}$ & 2.01 & -0.04 \\
\hline Concentration & 8 & $10 \%$ & -1.869 & -1.11 & 8 & $10 \%$ & -5.19 & 1.93 \\
\hline
\end{tabular}




\begin{tabular}{|l|l|l|l|l|l|l|l|l|}
\hline \multirow{2}{*}{$\begin{array}{l}\text { of PCL } \\
\text { solution }\end{array}$} & 8 & $12 \%$ & -1.667 & -1.71 & 8 & $12 \%$ & -3.82 & 0.81 \\
\cline { 2 - 9 } & 8 & $14 \%$ & 3.535 & 2.82 & 8 & $14 \%$ & 9.01 & -2.75 \\
\hline
\end{tabular}
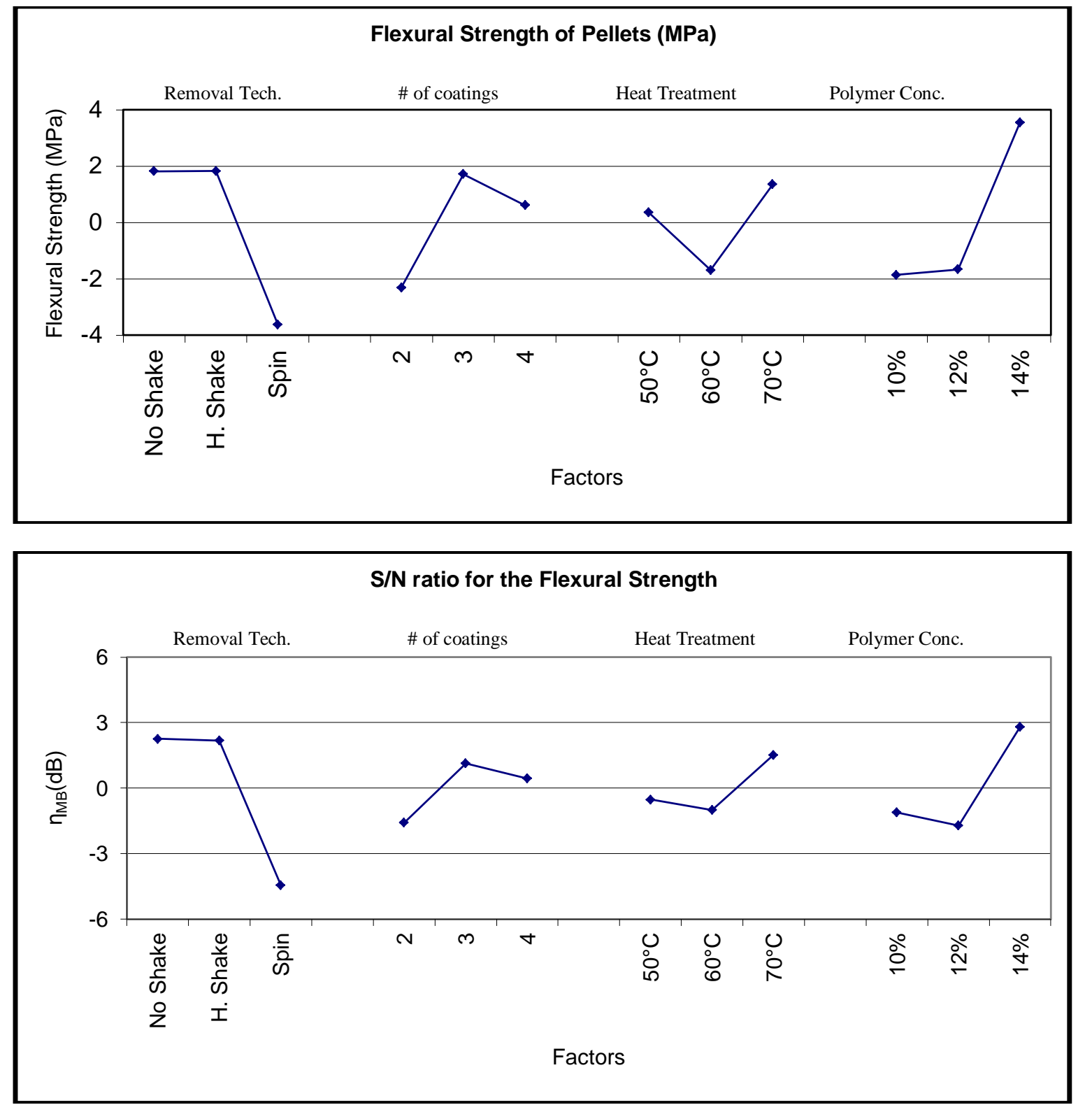

Figure 2-Parameter effects on the flexural strength (top) and $\eta_{\mathrm{MB}}$ (bottom) for the pellet samples.

Note: the zero value on the Y-axis represents the flexural strength mean-of-means value, which is calculated to be 8.28 MPa. The graphs show the effect and S/N ratio of the parameters on this value. 

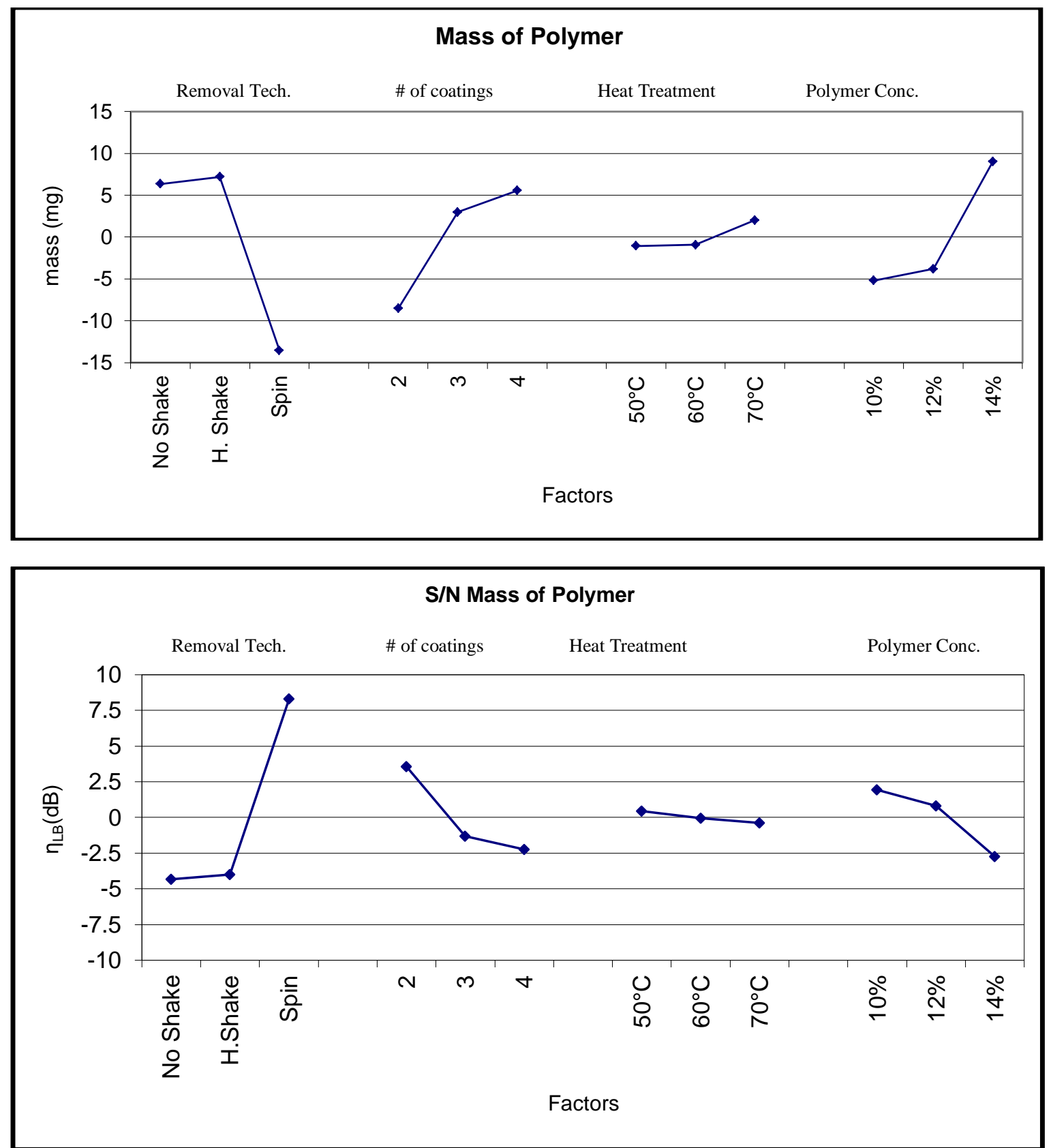

Figure 3-Parameter effects on the polymer mass (top) and $\eta_{\mathrm{LB}}$ (bottom) for the pellet samples.

Note: the zero value on the Y-axis represents the polymer mass mean of means value, which is calculated to be 19.1 $m g$. The graphs show the effect and $\mathrm{S} / \mathrm{N}$ ratio of the parameters on this value. 


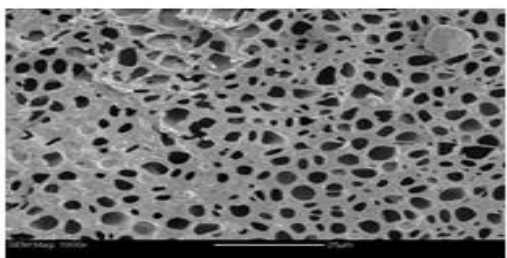

Irial 1.

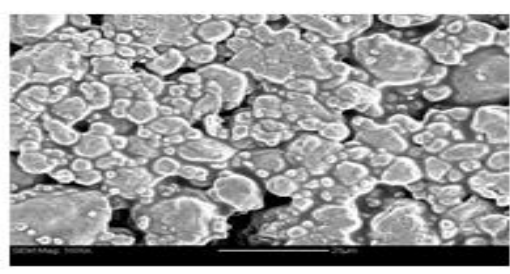

Trial 4.

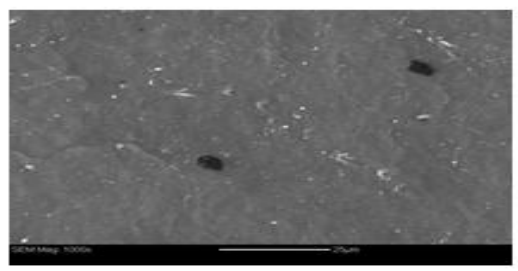

Trial 7 .

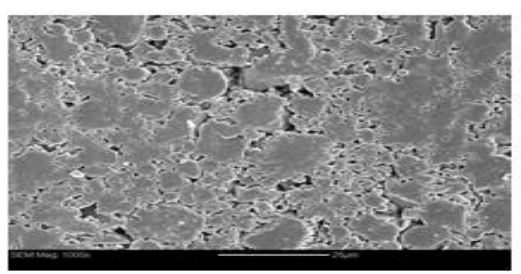

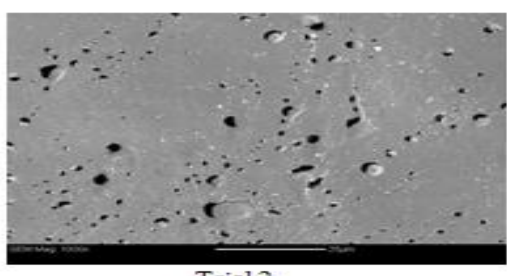

Trial 2.

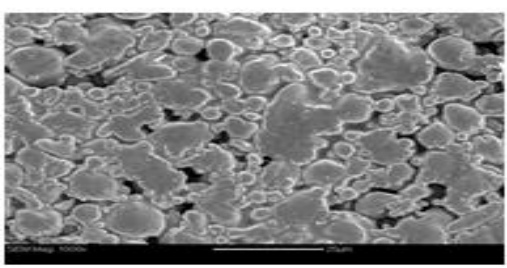

Trial 5

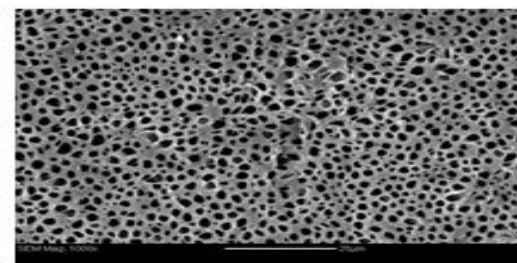

Trial \&.

The optimum pellet -

- Uncoated pellet.

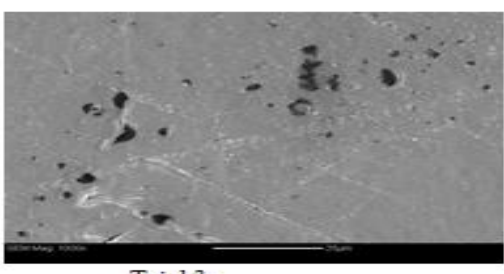

Trial 3.

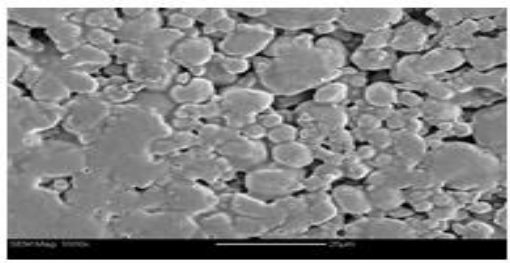

Trial 6 .

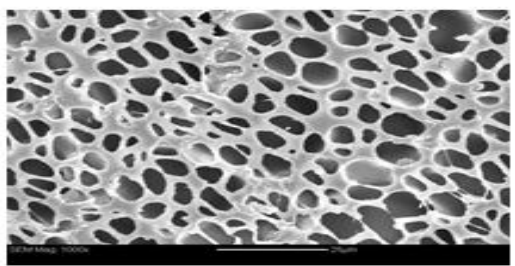

Trial 9.

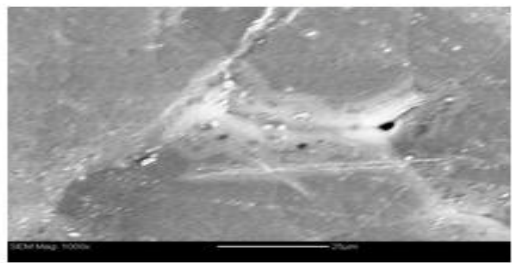

Figure 4-SEM surface micrographs for the all pellet samples trials.

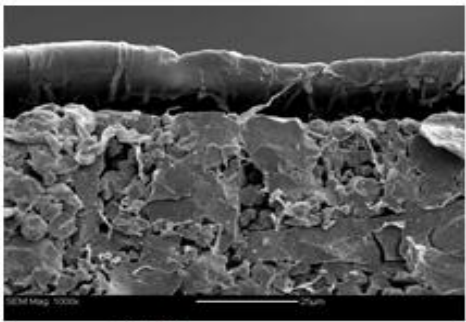

Trial 1.

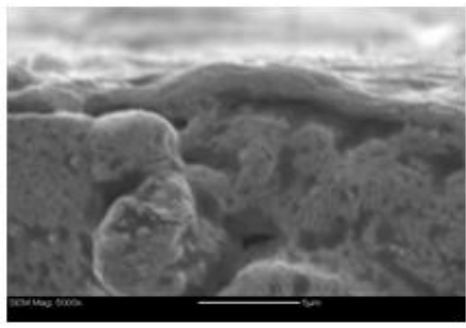

Trial 4.

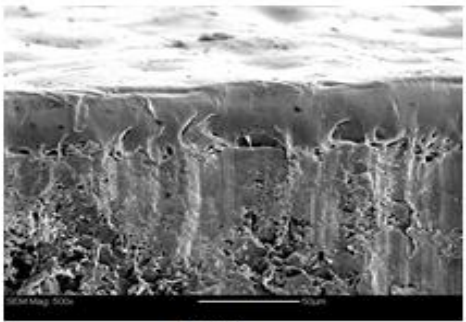

Trial 2.

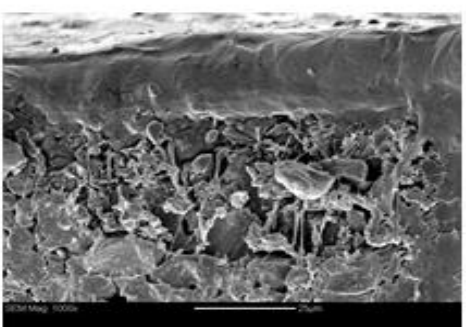

Trial 5.

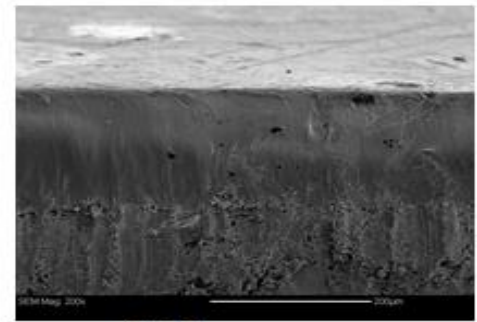

Trial 3.

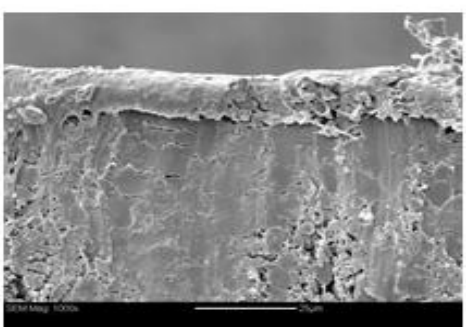

Trial 6. 


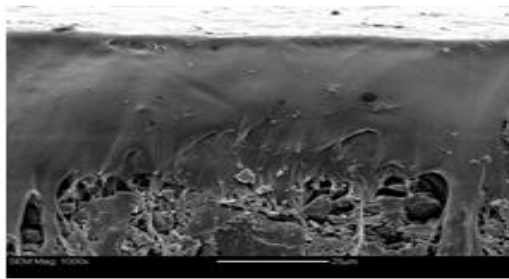

Trial 7.

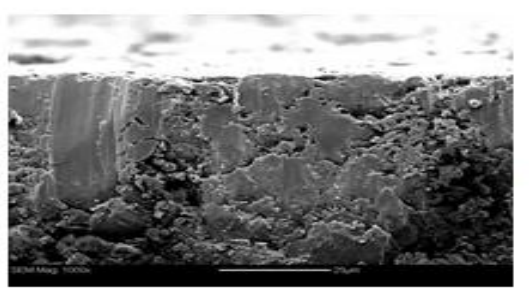

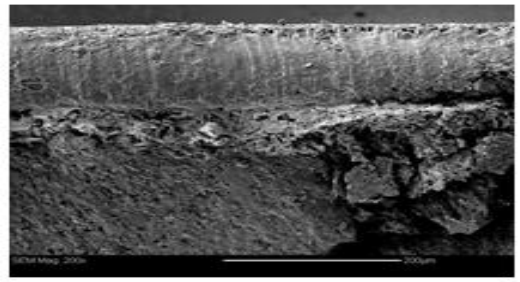

Trial \&.

The optimum pellet -

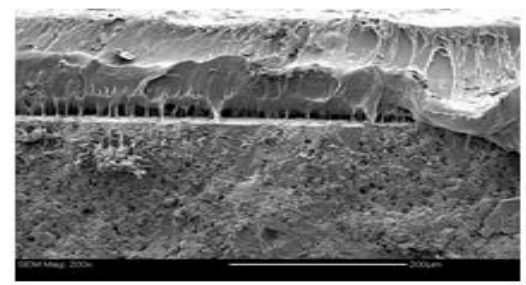

Trial 2.

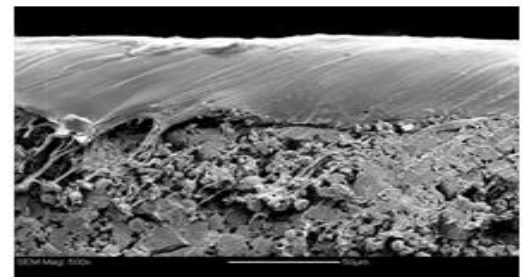

Figure 5 -SEM Micrographs of the cross-section of pellet samples coated with polymer for the all trials.

\section{The Optimum Experimental Conditions}

The experimental conditions having the maximum signal-to-noise ratio are considered the optimum, as the variability of any characteristic is inversely proportional to the $\mathrm{S} / \mathrm{N}$ ratio [1-8]. Consequently, the Taguchi method can determine the condition of least variability by the signal-to-noise ratio. Table 6 shows the optimum experimental conditions for the pellet samples for the flexural strength and the amount of polymer deposited on the samples. A confirming experiment should be conducted with the experimental conditions shown in Table 6. Table 7 illustrates the results of the confirming experiments. It is seen that all of the predicted results are reasonably close to the measured ones, indicating that the system behaved in a linear manner. In most of the nine cases, the predicted experimental condition yielded extremely good result, and these results were quite close to the predicted one. Therefore, the experimental conditions of Table 5 are the optimum conditions, which produce samples with 10.49 MPa flexural strength and mass of polymer $21.0 \mathrm{mg}$.

Table 6 -The optimum experimental conditions

\begin{tabular}{|c|c|c|c|c|c|}
\hline Response & \multicolumn{2}{|c|}{ Experimental Conditions } & & \multicolumn{2}{|c|}{ Experimental Conditions } \\
\hline \multirow{5}{*}{$\begin{array}{l}\text { Flexural } \\
\text { strength }\end{array}$} & Parameter & Level & \multirow{5}{*}{$\begin{array}{l}\text { Mass of the } \\
\text { polymer }\end{array}$} & \multirow{2}{*}{\begin{tabular}{|l} 
Parameter \\
Removal \\
\end{tabular}} & \multirow{2}{*}{$\begin{array}{l}\text { Level } \\
\text { spinning }\end{array}$} \\
\hline & Removal & no shaking & & & \\
\hline & \# of coats & 3 & & \# of coats & 2 \\
\hline & Heat treatment & $70^{\circ} \mathrm{C}$ & & Heat treatment & $50^{\circ} \mathrm{C}$ \\
\hline & Polymer Conc. & $14 \%$ & & Polymer Conc. & $10 \%$ \\
\hline
\end{tabular}

Table 7 -Parameters and levels of the confirming experiments

\begin{tabular}{|c|c|c|}
\hline \multicolumn{2}{|c|}{ Parameters \& Levels } & \multirow[b]{2}{*}{ Value } \\
\hline Response & Exp. Conditions & \\
\hline \multirow{5}{*}{$\begin{aligned} & \text { Flexural Strength } \\
& \bullet \text { Actual } \\
& \bullet \text { Maximum } \\
& \bullet \text { Measured } \\
& \bullet \text { Minimum }\end{aligned}$} & \multicolumn{2}{|c|}{ MPa } \\
\hline & \multicolumn{2}{|c|}{8.28} \\
\hline & $a_{1} b_{2} c_{3} d_{3}$ & 8.28 \\
\hline & $\mathrm{a}_{1} \mathrm{~b}_{2} \mathrm{c}_{3} \mathrm{~d}_{3}$ & 13.10 \\
\hline & $\begin{array}{l}\mathrm{a}_{1} \mathrm{~b}_{2} \mathrm{c}_{3} \mathrm{~d}_{3} \\
\mathrm{a}_{1} \mathrm{~b}_{2} \mathrm{c}_{3} \mathrm{~d}_{3}\end{array}$ & $\begin{array}{l}10.49 \\
2.33\end{array}$ \\
\hline \multirow{5}{*}{$\begin{aligned} & \text { Mass of Polymer } \\
& \text { - } \text { Actual } \\
& \bullet \text { Minimum } \\
& \bullet \text { Measured } \\
& \bullet \text { Maximum }\end{aligned}$} & \multicolumn{2}{|c|}{ mg } \\
\hline & \multicolumn{2}{|c|}{19.1} \\
\hline & $a_{3} b_{1} c_{1} d_{1}$ & 19.1 \\
\hline & $\mathrm{a}_{3} \mathrm{~b}_{1} \mathrm{c}_{1} \mathrm{~d}_{1}$ & 4.5 \\
\hline & $\begin{array}{l}a_{3} b_{1} c_{1} d_{1} \\
a_{3} b_{1} c_{1} d_{1}\end{array}$ & $\begin{array}{l}21.0 \\
35.3\end{array}$ \\
\hline
\end{tabular}


In addition, the yield strength / mass of $\mathrm{CaP}(\mathrm{MPa} / \mathrm{gm}$ of $\mathrm{CaP}$ ) was calculated and found to be $57.26 \mathrm{MPa} / \mathrm{gm}$ as a maximum flexural strength and $9 \mathrm{MPa} / \mathrm{gm}$ as a minimum flexural strength the samples could withstand before fracture. The yield strength / total mass of $\mathrm{CaP}+\mathrm{PCL}$, (MPa/gm) was calculated to be $49.42 \mathrm{MPa} / \mathrm{gm}$ as maximum flexural strength and $10.47 \mathrm{MPa} / \mathrm{gm}$ as a minimum strength. The total mass of polymer attached to the surface of the pellets was estimated to be $35.3 \mathrm{mg}$ as a maximum value, $4.5 \mathrm{mg}$ as a minimum value and it is measured to $21.0 \mathrm{mg}$.

\section{Conclusion:-}

The use of a statistical experimental design in conjunction with the Taguchi methodology of optimization, was found to be an effective method of optimizing the polymer coating process for the dense implants. The optimum experimental conditions were determined with high reproducibility, Table 5. Table 6 shows the results of the confirming experiments, the predicted, and the measured values of the responses. High quality dense implants were produced with a mean value of $10.49 \mathrm{MPa}$ flexural strength and approximately $21.0 \mathrm{mg}$ of polymer deposited on the samples. The flexural strength mean value of the uncoated pellets was $3.96 \mathrm{MPa}$.

\section{References:-}

1. Johnson N.L., Leone F.C., Statistics and Experimental Design, John Wiley \& Sons, 1977,12 - 30.

2. Barker T. B., Quality Engineering by Design: "Taguchi's Philosophy", Quality Progress, Vol.19/12 1986.

3. Saeed Maghsoodloo, Guttekin Ozdemir, Victoria Jordan, Chen-HsiuHuang, "Strengths and limitations of Taguchi's contributions to quality, manufacturing, and process engineering", Journal of Manufacturing Systems, Volume 23/ 2, 2004, 73-126.

4. M. Nataraj, V.P. Arunachalam, G. Ranganathan, "Using risk analysis and Taguchi's method to find optimal conditions of design parameters: a case study", The International Journal of Advanced Manufacturing Technology, 2006, V 27/5-6, 445-454

5. Byrne D.M. and Taguchi G., "The Taguchi approach to parameter design", American Society for Quality Congress, Anaheim, 1986.

6. Han-Xiong Li, XinJiang Lu, System Design and Control Integration for Advanced Manufacturing, J.wiley, 2014, 370-376

7. Taguchi G., System of experimental design, Vol. 1, edited by D. Clausing, UNIPUB/Kraus international publications, New York, 1987.

8. Vinitkumar K. Modi, Darshak A. Desai, Review of Taguchi Methodology, 2018, V5/1, JETIR (ISSN-23495162).

9. Ajaal Tawfik, Ph.D. thesis, Queen's University, Kingston, Ontario, Canada, 2002.

10. Reginald W. Smith \& Tawfik T. Ajaal, Technical Report, Development of skeletal composites of synthetic bone mineral and biodegradable polymers, submitted to Millennium Biologix Inc. (MBI), 2002.

11. Khan SN, Bostrom MPG, Lane JM, Tissue engineering in orthopedic surgery; bone growth factors, Orthopedic Clinics of North America, volume 31, number 3, 2000, 1 - 16.

12. Anant Mahapatra, and Wasim S Khan, Tissue Engineering in Orthopaedics and Musculoskeletal Sciences, Open Orthop J.5, 2011, $239-241$.

13. Flahiff CM, Blackwell AS, Hollis JM, Feldman DS, Analysis of biodegradable composite for bone healing, J Biomed Mater Res 31,1996, 419 - 414.

14. Zeeshan Sheikh, Shariq Najeeb, Zohaib Khurshid, Vivek Verma, Haroon Rashid and Michael Glogauer, Biodegradable Materials for Bone Repair and Tissue Engineering Applications, Materials 2015, 8, 5744-5794

15. Hollinger J, Battistone G., Biodegradable bone repair materials. Synthetic polymers and ceramics, Clin Orthop 1986, 207:290 - 305 .

16. XIAOHUA LIU and PETER X. MA, Polymeric Scaffolds for Bone Tissue Engineering, Annals of Biomedical Engineering, Vol. 32/3, 2004, 477-486.

17. Casaletto MP, Kciulis S, Mattogno G, Mezzi A, Ambrosio L, Branda F, XPS characterization of biocompatible hydroxyapatite-polymer coatings, Surface and Interface Analysis 34/1, 2002, 45 - 49.

18. Langstaff $\mathrm{S}$, et al.., Resorbable bioceramics based on stabilized calcium phosphates, Part II: Evaluation of biological response, Biomaterials 22 ,2001, $135-150$.

19. Williams DF., Biodegradation of surgical polymers, J Mater Sci; 17, 1982, 1233 -1246.

20. Prashant M. Satturwar, Suniket V. Fulzele, and Avinash K. Dorle, Biodegradation and in vivo biocompatibility of rosin: a natural film-forming polymer, AAPS Pharm SciTech. 2003, 434-439

21. Bostman OM. Current concepts review. Absorbable implants for fixation of fractures. J Bone Jt Surg (Am) 1991,73: 148 - 153 . 
22. Sushil Rangdal, Kanniraj M, Narendra Joshi, Rakesh Bhargava, Daljit Singh, Critical Evaluation Of Biodegradable Implants In Intraarticular Fracture Fixation: A Recent Experience In India, J. Orthopaedics 2010, 7(4)e 7

23. Williams DF., Mechanisms of biodegradation of implantable polymers. Clin Mater 1992; $10: 9-12$.

24. Hansoo ParkJohnna S. TemenoffAntonios G. Mikos, Biodegradable Orthopedic Implants, Engineering of Functional Skeletal Tissues, Springer, London, 2007,55-68

25. Daniels AV, Chang MKO, Andias KP, Heller J, Mechanical properties of biodegradable polymers and composites proposed for internal fixation of bone, J Appl Biomater 1, 1990, 57 - 78.

26. Gupta N, Kishore E, Bet W, Sankaran S, Studies on compressive failure features in synthetic foam material, J Mater Sci 36, 2002, 4485 - 4491.

27. Eyassu Woldensenbet, Narendra Sankella, Flexural Properties of Nanoclay Syntactic Foam Sandwich Structures, Journal of Sandwich Structures \& Materials, V.: 11 / 5: 5, 2009, 425-444

28. Amjad Z, editor. Calcium phosphates in biological and industrial systems. Boston, MA: Kluwer Academic Publishers, 1997, 529 - 539.

29. Sharon Kehoe, Calcium Phosphates for Medical Applications, Editor: Joseph T. Stokes Publishers: Dublin City University, 2008

30. Park JB, Bronzino JD, editors. Biomaterials. Principles and applications. Boca Raton: CRC Press, 2003.

31. Hench LL, Bioceramics. J Am Ceram Soc 1998, 81:1705 - 1728.

32. Suchanek W, Yoshimura M. Processing and properties of hydroxyapatite-based biomaterials for use as hard tissue replacement implants. J Mater Res 13,1998, 94 - 117.

33. Wojciech Suchanek, Masahiro Yoshimura, Processing and properties of hydroxyapatite-based biomaterials for use as hard tissue replacement implants, Journal of Materials Research, Publisher: Cambridge University Press (CUP), Volume: 13/1, 2011, 94-117.

34. Amass W, Amass A, Tigle B, A review of biodegradable polymers: uses, current developments in the synthetic and characterization of biodegradable polyesters, blends of biodegradable polymers and recent advances in biodegradation studies, Polymer International 47,1998, 89 - 144.

35. Richard Song, Maxwell Murphy, Chenshuang Li, Kang Ting, Chia Soo, and Zhong Zheng, Current development of biodegradable polymeric materials for biomedical applications, Drug Des Devel Ther. 12: 2018, 3117-3145.

36. Tencer AF, Mooney V, Brown KL, Silva PA, Compressive properties of polymer coated synthetic hydroxyapatite for bone grafting, J Biomed Mater Res 19,1985, 957 - 969.

37. A. F. Tencer V. Mooney K. L. Brown P. A. Silva, Compressive properties of polymer coated synthetic hydroxyapatite for bone grafting, https://doi.org/10.1002/jbm.820190807

38. Lias B-P, Polymer in controlled drug delivery, Biomaterials, www.devicelink.com/mpb/archive/97/11/003.html.

39. Brekke JH, A rational for delivery of osteoinductive proteins, Tissue Engineering, volume 2/ 2 ,1996, 97 - 114.

40. Ziyad S. Haidar, Reggie C. Hamdy, Maryam Tabrizian, Delivery of recombinant bone morphogenetic proteinsfor bone regeneration and repair. Part A: Current challenges in BMP delivery, Springer Science +Business Media B.V. 2009

41. Ikada Y, Tsuji H, Biodegradable polyesters for medical and ecological applications, Macro mol Rapid Commun 21, 2000,117 - 132.

42. Peter SJ, Miller MJ, Yasko AW, Yaszemski MJ, Mikos AG, Polymer concepts in tissue engineering, J Biomed Mater Res Applied Biomaterials 43 ,1998, 422 - 427.

43. Naseer Iqbal, Abdul Samad Khan, Anila Asif, Muhammad Yar, John W. Haycock, \& Ihtesham Ur Rehman, Recent concepts in biodegradable polymers for tissue engineering paradigms: a critical review, Journal International Materials Reviews, V. 64/2, 2018, 91-126

44. Hutmacher DW, Schautz T, Zein I, Ng KW, Teoh SH, Tan KC, Mechanical properties and cell cultural response of polycaprolactone scaffolds designed and fabricated via fused deposition modeling, J Biomed Mater Res 55 ,2001, $203-216$.

45. Marco Domingos, Dinuccio Dinucci, Stefania Cometa, Michele Alderighi, Paulo Jorge Bártolo, and Federica Chiellini, Polycaprolactone Scaffolds Fabricated via Bioextrusion for Tissue Engineering Applications, International Journal of Biomaterials, 2009, Article ID 239643, 9 pages

46. Lewis G, Mladsi S, Correlation between impact strength and fracture toughness of PMMA-based bone cement, Biomaterials 21, 2000, $775-781$.

47. E. Bialoblocka, Juszczk, M. Baleani, L. Cristofolini, M. Viceconti, Fracture properties of an acrylic bone cement, Acta of Bioengineering and Biomechanics, Vol. 10, No. 1, 2008, 21-26. 
48. Rizzi SC, Heath DJ, Coombes AGA, Bocvk N, Textor M, Downes S, Biodegradable polymer / hydroxyapatite composites: surface analysis and initial attachment of human osteoblast, J Biomed. Mater Res 55, 2001, 575 486.

49. S.J. Heo, S.E. Kim, Y.T. Hyun, D.H. Kim, H.M. Lee, J.W. Shin1, Y.M. Hwang1, J.W. Shin1, Biodegradable composite of poly s-caprolactone/hydroxyapatite 3-D scaffolds for bone tissue engineering, 3rd Kuala Lumpur International Conference on Biomedical Engineering 2006, 672-675

50. Zhong-Bei J, Min-li J, Feng-Wang Z, Chang-le J, Guo-Wang S, Polycaprolactone-poly(ethylene-glycol) block polymer IV: Biodegradable behavior in vitro and in vivo, Polymers for Advanced Technologies, volume 8, (1996) $693-696$.

51. Haiying Yu, Paul H Wooley \& Shang-You Yang, Biocompatibility of Poly-e-caprolactone-hydroxyapatite composite on mouse bone marrow-derived osteoblasts and endothelial cells, Journal of Orthopaedic Surgery and Research volume 4, Article number: 5 (2009)

52. Langstaff S, Sayer M, Smith TJN, Pugh SM, Hesp SAM, Thompson WT, Resorbable bioceramics based stabilized calcium phosphate, Part I: Rational design. Sample preparation and material characterization, Biomaterials 20(1999) 1727 - 1741.

53. Masanobu Kamitakahara, Chikara Ohtsuki, Toshiki Miyazaki, Review Paper: Behavior of Ceramic Biomaterials Derived from Tricalcium Phosphate in Physiological Condition, Journal of Biomedical Applications, Volume: 23/3, 2008 197-212. 